\title{
The Impact of the COVID-19 Pandemic on Consumer Behavior and Companies' Internet Communication Strategies
}

\author{
Arzhanova K.A. ${ }^{1}$ Beregovskaya T.A. ${ }^{2 *}$ Silina S.A. ${ }^{3}$ \\ ${ }^{1}$ Department of Advertising and Business Communications, Peoples' Friendship University of Russia (RUDN \\ University), Moscow, 117198, Russia \\ ${ }^{2}$ Marketing Department, State University of Management, Moscow, 109542, Russia \\ ${ }^{3}$ Service marketing and brand management Department, State University of Management, Moscow, 109542, Russia \\ *Corresponding author. Email: tbereg@gmail.com
}

\begin{abstract}
In the modern world, social networks have become one of the main means of communication with consumers. Because of the COVID-19 pandemic, people have become distanced and the role of the Internet has increased more than ever. This channel has become a key means of communication for people. Social networks have become more actively used by companies as platforms for displaying content and communicating with consumers. Consumer behavior has also changed. The article will examine this change, the impact of the pandemic on social networks, digital marketing strategies, and specific examples of how companies used social media marketing strategies during COVID-19. Recommendations will also be offered for adapting digital marketing strategies to changes in consumer behavior.
\end{abstract}

Keywords: COVID-19, consumer behavior, Internet communication strategies, Social Media Marketing,

social networks, advertising

\section{INTRODUCTION}

Epidemics are not a new phenomenon in world history. The most famous of the latter are: Ebola, SARS, MERS, swine flu and dengue fever [1]. They affected two categories of human behavior: consumer behavior [2] and health risk mitigation behavior [3]. Despite this, a pandemic of the scale and economic impact of COVID-19 has not been observed for a century. Pandemics can have serious macroeconomic consequences: rising unemployment, economic decline, and uncertainty.

Research of previous catastrophes and epidemics have focused on motivating and protecting people's health [4-7] rather than consumer behavior.

Previous studies of behavior during epidemics have identified behavior change as a result of individual motivation and government policies [8].

In the 21 st century, there are means of exchanging information that were not available during previous epidemics. Social networks are a good way for companies to keep in touch with consumers.

The outbreak of the COVID-19 pandemic has impacted many different sectors in business. Not only retailers are suffering from the consequences, but also the E-Commerce sector is experiencing a slump in sales. Due to "Social Distancing" it is observed that more and more people spend their time online. Social Media platforms are mostly used and enable the people to see more content from certain companies. This is reflected by the online activity of followers of Brand sites having increased by $16.1 \%$, compared to the last full week of February [9].

While no one can yet predict what post-coronavirus reality will look like for marketers, one thing is certain: in an environment where physical interactions are limited for an extended period of time, digital channels are more important than ever. Based on what has been observed in countries severely affected by the pandemic, online channels will play an increasingly key role when the majority of the population is confined. In Italy, where the overwhelming number of cases resulted in a complete lockdown, Internet traffic exploded. This is where marketers can make a difference. Marketing technologies will be essential when providing consumers with the type of personalized, relevant, and current information they are looking for on the Web. The same goes for the empathy that will accompany the responses to a series of new restrictions and needs that will be imposed on them. At the moment, brands and businesses are rushing to change their marketing tactics to meet their business goals in this unfamiliar environment. We will therefore see how companies have been sharing information and interacting with others on social media and the different digital marketing strategies to adapt during the coronavirus pandemic because in our digital world, there are plenty of ways to stay connected to your customers through and keep your business going through it. 


\section{METHODOLOGY}

The novelty of the work is that there have been no previous studies of digital marketing strategies of companies during the COVID-19 pandemic.

Theoretical methods: analysis, synthesis, schematization, abstraction, categorization. Empirical research method: document analysis.

\section{RESULTS}

In March 2020, when the COVID-19 virus turned into a pandemic, consumers around the world were buying toilet paper and food $[2,10]$.

The changes in consumer behavior impacted not only grocery stores, convenient stores, cafeterias, and restaurants but also their suppliers. It is important for at least three reasons for retail and consumer services to understand the underlying processes and reasons that led to the reported unusual behavior: first, to be able to better react to similar situations in the future; second, to help the currently suffering retail and consumer services to deal with the ongoing COVID-19 pandemic; and third, to provide knowledge for an optimal transition to the new status quo of consumer and retail services that is expected to emerge once the COVID-19 pandemic is curbed [11].

When studying the consequences of the spread of the situation with coronavirus in Russia, various studies were considered on changes in spending by Russians compared to 2019 .

Russian standard Bank's research shows that the total amount of transactions on Russian Standard Bank cards in the last week of March 2020 increased by $47 \%$ compared to the same period in 2019. The total amount of transfers by cards - by 59\%. The amount of transactions in the "transport and travel" category fell by $51 \%$, while the number of transactions decreased by $10 \%$ [12].

Sberbank also analyzed changes in spending by Russians compared to 2019. According to the data received, spending by Russians in July reached the level of 2019 for the first time since the beginning of the pandemic, which was largely due to social payments. The total number of operating retail and service outlets as of the end of July is only $1.4 \%$ less than in February. At the same time, $7.5 \%$ of service sector organizations and $3.8 \%$ of non-food stores have not yet opened. At the same time, food stores increased by $7 \%$. Business adapted to the restrictions imposed, and during the period of self-isolation, companies changed from non-food to food, from service to retail, which allowed them to continue working during the crisis. In the event of a second wave or new restrictions, these companies will be safe.

Thanks to these changes, there has been an increase in spending by Russians on food products. Spending on nonfood items remains significantly higher than last year - it increased by $10.1 \%$, driven by household appliances, electronics and automobiles. Demand for services is $17.6 \%$ lower than a year ago (figure 1).

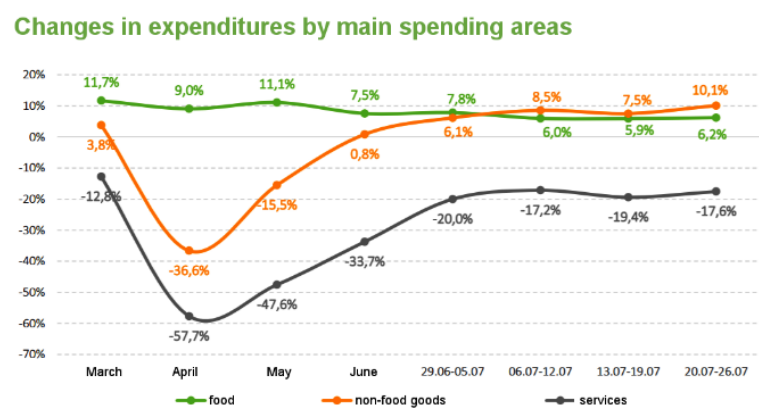

Figure 1 Changes in expenditures by main spending areas (Source: Sberbank, 2020)

The consumer activity index, which characterizes the variety of categories of goods and services in the basket of buyers, fell to 74.7 points, which indicates a less diverse structure of purchases and the fading recovery momentum [13].

As for the most popular products - for the last seven months of 2020, Russians in food stores "Pyaterochka" and "Magnet" most often bought bananas, sugar and potatoes, according to the analytical division "Chekskan Research" [14].

The COVID-19 pandemic has had an impact on social networks and interaction of companies with them. "Socialbakers", which is a trusted social media partner to many enterprises and SMBs, recently published the State of Social Media Report: The Impact of COVID-19 on its website [15]. This report deals with the scrutinization of interaction between companies and users during COVID-19 [9]. Its goal is to help marketers during this crisis so they come out stronger after. It starts out with the shift in usage of Instagram and Facebook, moves on to Coronavirus Content online and ends with information and numbers about Advertising in times of COVID-19 [15].

\subsection{State of Engagement on Facebook and Instagram}

Figure 2 shows a picture which visualizes the median post interactions on Instagram for worldwide Brand accounts in 2019 vs. 2020. Countries like Japan (10\%) and Argentina $(2.2 \%)$ witnessed an increase in interaction whereas Belgium for example remained at the same level. However, most countries in Europe, the Middle East and North America are witnessing a decline, e.g. UK (10.5\%), the U.S. $(13.8 \%)$ and Israel (29.5\%). 


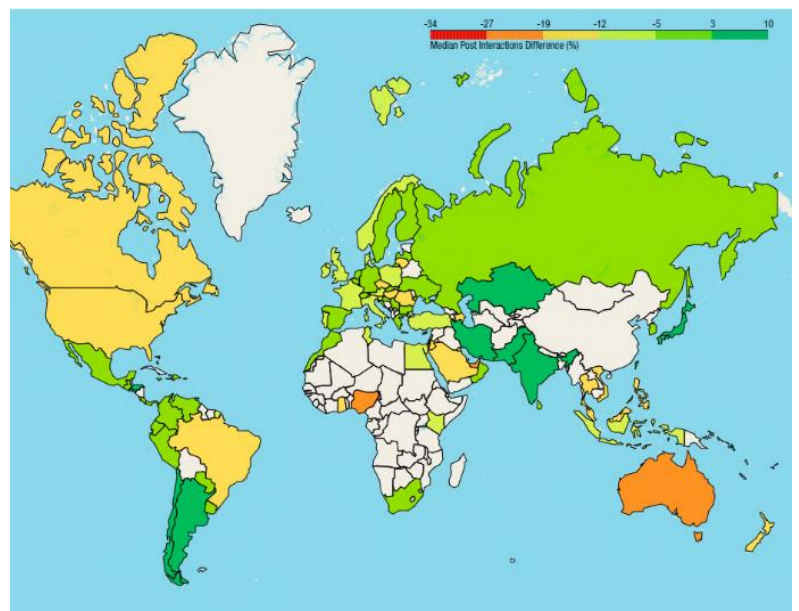

Figure 2 The State of Engagement on Instagram (Source: Socialbakers, 2020)

Figure 3 shows the median post interactions on Facebook for worldwide Brand accounts in 2019 vs. 2020 are being visualized. Austria (7.7.\%) and Japan (3.3\%) witnessed an increase while Switzerland and Ireland remained at the same level. Again, many countries in Europe and North America witnessed a decrease, e.g. Italy (3.6\%), the U.S. $(6.7 \%)$ and Sweden (15\%) [15].

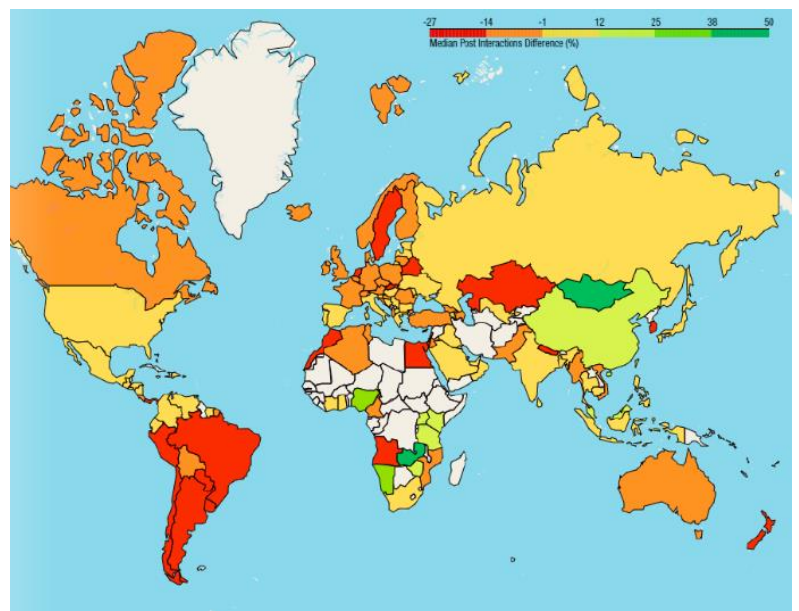

Figure 3 The State of Engagement on Facebook (Source: Socialbakers, 2020)

\subsection{COVID-19 Content on Social Media}

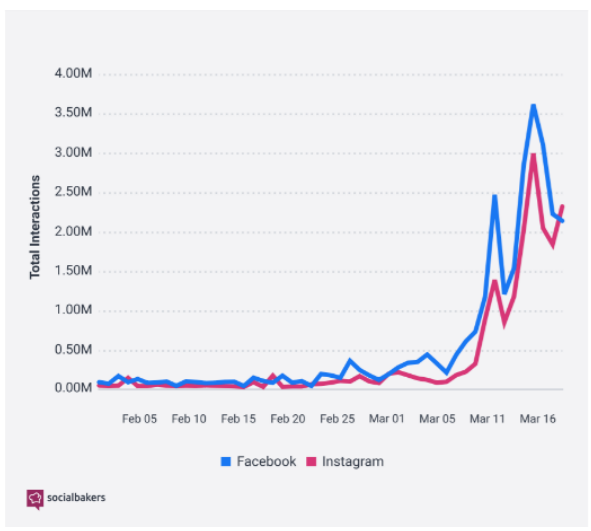

Figure 4 Evolution of total Interactions (Source: Socialbakers, 2020)

As can be seen in Fig. 4, the mentioning of coronavirus picked up in March and started to increase rapidly in the following days. One of the largest increases can be witnessed on March 16th. On this day New York's major ordered that all the bars, theatres and cinemas in the city are supposed to close in response to increasing Coronavirus cases in the United States. Many other countries also closed their borders. These developments meant change for a lot of brands. Figure 5 presents the evolution of total posts regarding the Coronavirus on Facebook and Instagram. The Coronavirus has been mentioned more on Facebook which suggests that users are turning to Facebook rather than Instagram for news and updates. However, both platforms offer them [15].

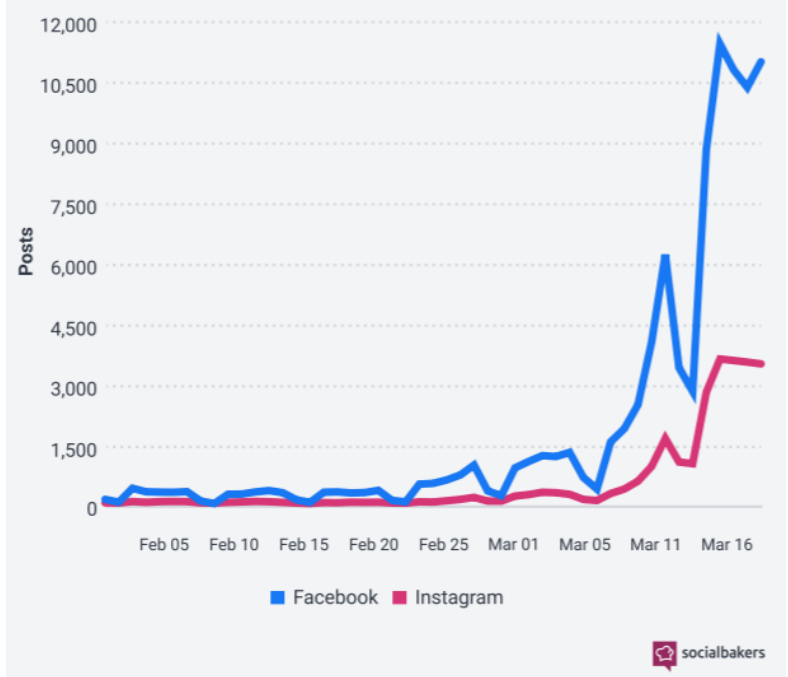

Figure 5 Evolution of Total Posts for Coronavirus Content on Facebook and Instagram (Source: Socialbakers, 2020) 
In early March Facebook users started to react to coronavirus-related content on Brand pages with more love reactions. This coincides with the fact that many brands started to post messages of support or showed how they were helping communities during COVID-19. This suggests that the users appreciate that the brands they follow are so considerate of the ones in need. The Facebook posts that got the most engagement were all from brands that suggested steps for fighting COVID-19 or that were supporting their employees in this time of crisis.

In 2020 brands across the globe have been consistently posting lesser pieces of paid content. This cannot be attributed to Covid-19 only, but it is related to a tightening of budgets. The trend of posting more organic posts will most likely continue due to COVID-19 because companies will be looking for less costly advertising opportunities.

Due to "Social Distancing" Facebook users have been spending $11.9 \%$ more time online from March 16 until 22 in comparison with the last seven day of February [15].

\subsection{Advertising in times of COVID-19}

Looking at 5 regions globally (East Asia, Southeast Asia, Northern America, Western Europe, and Southern Europe) it becomes clear that all of them had to witness a decrease in ad spend due to the pandemic. East Asia creating an exception because brands have started to recover and in this particular region ad spend has increased by $21.5 \%$ in the beginning of March. This could suggest that soon the brands in other regions can witness this change, too, as soon as they survived the worst part of the pandemic [15].

\subsection{Social Media Marketing}

Thanks to social media, the way companies manage their businesses has changed. Social media technologies, channels, and software are used to create, transmit, and deliver messages. Trends in social networks affect the company's advertising plans. During COVID-19, this became particularly relevant.

\subsubsection{Advantage: Higher Usage}

As already mentioned before, Social Media Usage has increased due to "Social Distancing" [9]. The social media site "Reddit" reported a higher usage by $20-50 \%$ whereas also "TikTok" notes an increase in usage by $27 \%$ from February to March alone [16].

\subsubsection{Advantage: Making a Positive Impact}

News and statistics concerning COVID-19 make a lot of people feel insecure and lost. In order to keep the customers engaged, a business needs to convey the message that they are either doing good for the community or sharing content that makes people feel good [16].

\subsubsection{Advantage: Makes up for In-Person Business}

With many retail locations closing during COVID-19, many customers turn to online shopping [16].

\subsubsection{Advantage: Current Strategies can remain useful in the future}

There will come a time when things go back to normal and some of the methods that were put into place rather quickly can be continued once the pandemic is over. They can help with moving forward [16].

Three Examples of how Companies utilized Social Media Marketing strategies during COVID-19

Example One: Domino's

The American pizza restaurant chain "Domino's" was one of the first companies during the pandemic that utilized the platform "Zoom" in order to create a recruiting commercial. The video was published on YouTube on their own channel [17]. It involves different employees addressing possible recruits and emphasizing how in this situation it does not only help others but also themselves. It conveys a huge message since many people are out of work due to COVID19.

Example Two: Nike

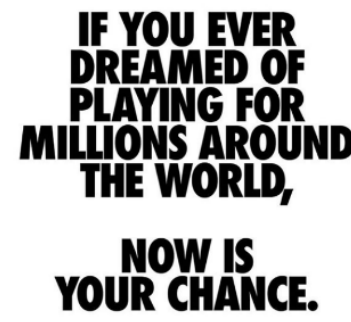

Play inside, play for the world.

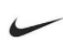

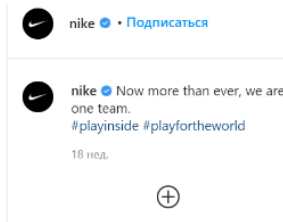

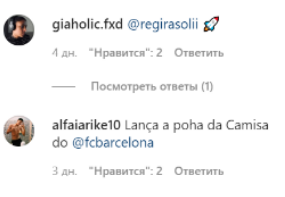

$\bigcirc \bigcirc \nabla$

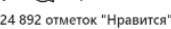

Figure 6 Nike's Instagram post (Source: Nike, 2020)

As can be seen in the picture above, Nike has used its social media platform for amplifying public health messaging around social distancing and hand washing. Their post is also formulated in such a way that it is connected to the subject their products are based on which is sports. This post was liked by over 500.000 users on Instagram [18].

Example Three: Home Bargains

As COVID-19 affects many companies' staff in forms of layoffs, furloughs, increased hours and in some cases 
hazardous working conditions. If a company acknowledges these struggles on Social Media it can serve as a boost for its staff and give consumers a better understanding of the working situation of the employees. It is a good start, but the American discount store chain "Home Bargains" took it to another level. In their Facebook post the company mentioned the concrete steps they were taking in order to acknowledge and help their staff. Additionally, in the second half of their post, "Home Bargains" also addressed its customers directly and gave them more information about a changed shopping experience in their stores (Figure 7).

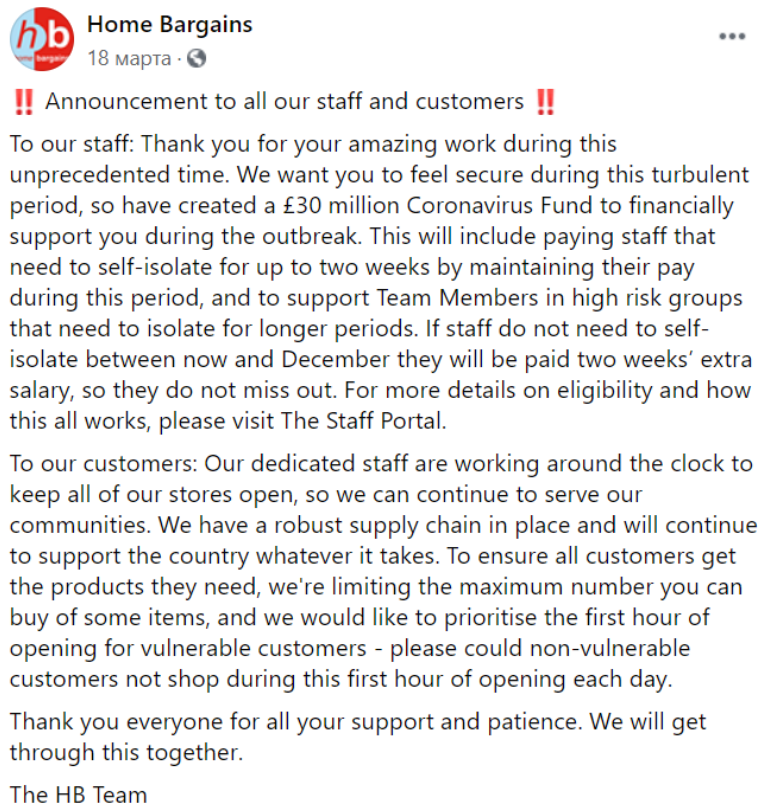

To our customers: Our dedicated staff are working around the clock to keep all of our stores open, so we can continue to serve our communities. We have a robust supply chain in place and will continue to support the country whatever it takes. To ensure all customers get the products they need, we're limiting the maximum number you can buy of some items, and we would like to prioritise the first hour of opening for vulnerable customers - please could non-vulnerable customers not shop during this first hour of opening each day.

Thank you everyone for all your support and patience. We will get through this together

The HB Team

Figure 7 Home Bargains Facebook Post (Source: Home Bargains, 2020)

The post generated over 140.000 reactions and also got very positive comments [19].

Examples of some strategies used by companies during a pandemic can be given.

Free Access to Paid Content

Giving free access to membership or premium content is one of the first strategies that most brands employed at the very beginning of the new pandemic marketing.

A few examples of them:

- HBO opened free access to nine original series, 20 movies, and 9 documentaries.

- Nikon made its 10 classes of online photography free until the end of April.

- Gucci teamed up with Yuko Higuchi and released a free-to-download digital sketchbook that includes coloring pages, games, and more.

- The Museum of Modern Art launched a series of free online courses on fashion and design.
- Ministry of Tourism and Antiquities of Egypt launched \#ExperienceEgyptFromHome: a series of free online tours in the tombs of pharaohs.

Apart from actually helping people, such a strategy has a lot of benefits for their digital marketing:

- It contributes to brand recognition

- Keeps people engaged with the brand

- Generates publicity and media coverage

- Works for the product as a free trial period

- Spreads the word of mouth.

Offline Experience as a New Product

Such industries like traveling and tourism, airlines and transportation, sports and entertainment, outdoor activities, events, rental services, insurance, and property market suffer the most during the crisis. Some companies have stopped their marketing at all, and some have paused most promotional campaigns and switched to educational and entertainment content in order to keep the conversation alive.

However, there are few companies that are trying to adapt their seemingly offline services to a new reality.

- Airbnb has launched Online Experiences where you can enjoy a number of activities without leaving your house.

- Chipotle has launched a series of Zoom lunch parties featuring celebrity guests, with free entree giveaways included.

- New York City's grooming studio Barba has launched the Quarancuts Virtual Hair School. You can learn to do men's haircuts at Zoom classes and even get an (amateur) certificate.

It is hard to predict whether such innovations will be effective enough to help companies stay afloat. And if any of such experimental products proves to be successful, it can be left in the company portfolio even after the crisis.

Creativity with original social campaigns

With the period of confinement and health crisis of COVID19 , many brands and advertisers adapt their communication to the imperatives of the period. And in most cases, these exceptional campaigns are sober, clear, and effective. Some businesses even managed, with low-cost means, to make it known that they continued to exist, even with their shops closed.

- \#ArtOfQuarantine by Looma for Ministry of Culture and Information Policy of Ukraine;

- Instagram has launched a series of "Stay Home" stickers to encourage people to stay inside.

Adapting the offer

Adapting the offer is essential, the date of return to normal is still very unclear, it is important to think about adapting the offer now to be ready in case of extension.

\section{DISCUSSION}

To adapt digital marketing strategies to changes in consumer behavior, we offer the following recommendations.

1. Being proactive and inform 
In the face of a crisis of any kind, in this case a health crisis, the important thing is to be well prepared. And if not, companies need to be proactive, anticipating future questions from their clients. They must not leave customers in the dark. In this kind of crisis, we must not pretend that nothing is happening, but rather inform about the position taken by the company. Indeed, each brand has its role to play in this period of confinement related to the Coronavirus epidemic. Each company, on its own scale, can influence its audience on precautionary measures to take in the face of the COVID-19 epidemic. So, they need to quickly inform the customers about the steps taken within the company to respond to the crisis. Through their social networks, a newsletter, inform customers about the new organization. Telling them if their point of sale remains open or closed, the new opening hours, the precautionary measures put in place within the shop. If they have a website, they can put a message on the home page indicating the organization conditions of the company. If they have an e-commerce site, indicate if they still insure online orders and home deliveries. Crisis communication requires being reactive to make decisions quickly.

2. Reassuring and telling the truth

Avoiding talk in an emergency. Each of the communications must be thought through beforehand and the information verified, to keep the trust of the audience. On the contrary, companies must reassure about the awareness of the critical situation and the measures taken during this health crisis. Communicate about their actions, to show their customers that they are always available, even during this time of health crisis. That their team is engaged to answer their questions and continue to provide quality customer service. During confinement, social networks become a widely used means of informing and communicating with the public. The company must therefore be present and reactive on its social networks to answer customers' questions. During this period of Coronavirus containment, customer service must be more than ever perfectly managed to provide quality responses to their customers.

3. Empathy and Support

These are essential for a nowadays marketing plan. There is no need to praise dedication and effort in each message. However, telling the customers what they plan to do to help the community navigate through the crisis. It will serve as a proof of that they have made the right choice putting their trust in this brand, and engage more people willing to participate in whatever they are running.

What to tell:

- Social initiatives

- Support for local communities

- Support of frontline workers

- Donation

- Charitable collaborations

- Volunteering

- Help to seniors

- How people can commit

4. Email Marketing on COVID-19 crisis
As usual, any email strategy employ depends on the type of company, service, and audience. Healthcare, social services, deliveries, and retailers of food essentials are facing big challenges due to heavy workload, meaning they have totally different marketing strategies. On the other hand, travel agencies, transportation services, entertainment, and event industries handle a lot of cancellation and refund issues, and the load on all communication channels is huge as well. The rest of the businesses that are not on a frontline right now need to revise their email marketing approaches, and these are the steps suggested:

1. Sending only important COVID-19 updates

Not sending for the sake of sending. We have all seen enough of COVID-19 in our Inboxes, social media feeds and everywhere else. So, do not add to the tension with another Coronavirus urgent!! subject line. Reach out only if there is really important news that affects the work operation, shipment, return policy, etc., for example:

- Store closure

- Changes in online order management if any

- Changes in-app orders

- Changes in price policy

- Possible problems with delivery due to a high demand or transport restrictions

- Volunteering services that might be offering for seniors

- Assistance programs to customers in need, etc.

Just saying how they care about everyone's well-being is not what people want to hear from them right now. It is expected that they do it on a regular basis.

2. Avoiding long text-only copies

People will not read ten-paragraph emails that do nothing but remind of the sender's existence. Do not write to simply make self-apparent statements (We're in it together. We care about you. We care about our staff. We are here to serve. Isn't this how you always run business?). The content should be helpful, informative, or entertaining.

3. Showing empathy and asking if people feel like hearing from them

Asking people if they want to somehow update their preferences or pause some kinds of messages for a while. Also, ask what kind of content they would like to receive during the quarantine. It is important to not be afraid of mass unsubscribes. Empathy and compassion are always appreciated.

4. Segmenting the audience

This is when segmentation is more important than ever. An international brand should monitor the situation in each country it operates in and adjust the strategies correspondingly. Pay special attention to countries that struggle the most: Italian, French, and Spanish subscribers are hardly thinking about shopping right now.

5 . Not capitalizing on anxiety

Many businesses, like booking platforms, travel companies, hotels, cinemas, took an especially big hit. But staying respectful and caring of customers should still be a priority. They should not take advantage of panic and stress by selling "illness prevention wellness programs," "antivirus supplements," or "silver ion masks to battle pandemic." Of 
course, they should take advantage of any little demand that is still around to make money but not by manipulating people's fears and anxiety.

5. Online shopping

Pay attention to online shopping. The COVID-19 pandemic has encouraged older people to shop online for the first time [20].

McKinsey \& Company recently conducted a study of purchasing behavior in the United States. Consumer intent to shop online continues to increase, especially in essentials and home-entertainment categories. More interestingly, these habits seem like they're going to stick as US consumers report an intent to shop online even after the COVID-19 crisis [21].

\section{CONCLUSION}

All in all, one can say that COVID-19 definitely has changed the behaviour of consumers and the way they shop. The thorough analysis of social media usage has shown how COVID-19 not only affects the people's lives offline, but also online. Increased usage of social media exposes them to different sources of information and different opportunities for buying the things they need even when retail shops are closed. Unfortunately, many companies are facing a decrease in sales and employees are out of work, but looking at the numbers in East Asia can serve as an encouragement that better days are to come in the near future once the worst bit of the pandemic is over. Furthermore, COVID-19 has innovated the way companies interact with their customers online. During this pandemic companies have utilized Social Media Marketing in such a way that they not only sell their products, but also take on a role as an amplifier and supporter. These new tactics do not need to end once the pandemic is over. They can be enhanced further and adapted to normal times and could give the companies new ideas for their marketing.

\section{REFERENCES}

[1] M. Balinska, C. Rizzo, Behavioural responses to influenza pandemics: what do we know? PLoS Curr., 1 2009.

[2] S.M. Miri, F. Roozbeh, A. Omranirad, S.M. Alavian, Panic of buying toilet papers: a historical memory or a horrible truth? Systematic review of gastrointestinal manifestations of COVID-19. Hepat. Mon., 20 (3), 2020.

[3] G. La Torre, D. Di Thiene, C. Cadeddu, W. Ricciardi, A. Boccia, Behaviours regarding preventive measures against pandemic H1N1 influenza among Italian healthcare workers, October 2009, Euro Surveill., 14 (49), 2009, p. 19432.
[4] A.E. Gamma, J. Slekiene, G. von Medeazza, F. Asplund, P. Cardoso, H.J. Mosler, Contextual and psychosocial factors predicting Ebola prevention behaviours using the RANAS approach to behaviour change in Guinea-Bissau. BMC Publ. Health, 17 (1) 2017, p. 446. DOI: 10.1186/s12889-017-4360-2

[5] G.J. Rubin, R. Amlôt, L. Page, S. Wessely, Public perceptions, anxiety, and behaviour change in relation to the swine flu outbreak: cross sectional telephone survey, BMJ, 339 (7713), 2009, p. 156. DOI: 10.1136/bmj.b2651

[6] H. Seale, M.L. McLaws, A.E. Heywood, K.F. Ward, C.P. Lowbridge, D. Van, et al., The community's attitude towards swine flu and pandemic influenza, Med. J. Aust., 191 (5), 2009, pp. 267-269. DOI: 10.5694/j.1326-5377.2009.tb02781.x

[7] T. Timpka, A. Spreco, E. Gursky, O. Eriksson, Ö. Dahlström, M. Strömgren, et al., Intentions to perform non-pharmaceutical protective behaviors during influenza outbreaks in Sweden: a cross-sectional study following a mass vaccination campaign, PloS One, 9 (3), 2014, e91060. DOI: 10.1371/journal.pone.0091060

[8] W. Zhang, H. Gu., R.R. Kavanaugh, The impacts of SARS on the consumer behaviour of Chinese domestic tourists. Current Issues in Tourism, 8 (1), 2005, pp. 2238. DOI: $10.1080 / 13683500508668203$

[9] Internet resource:

https://business.trustedshops.de/blog/e-commercekompakt-2020-14/ (Date of circulation: 03.08.2020).

[10] C. Wang, R. Pan, X. Wan, Y. Tan, L. Xu, R.S. McIntyre et al., A longitudinal study on the mental health of general population during the COVID-19 epidemic in China. Brain Behavior, and Immunity, 87, 2020, pp. 40-48. DOI: 10.1016/j.bbi.2020.04.028

[11] S. Laato, A.K.M.N. Islam, A. Farooq, A. Dhir, Unusual purchasing behavior during the early stages of the COVID-19 pandemic: The stimulus-organism-response approach. Journal of Retailing and Consumer Services, 2020, 57, 102224 .

[12] Internet resource: https://plusworld.ru/daily/catanalytics/russkij-standart-rasskazal-o-tratah-rossiyanpo-kartam-v-marte/ (Date of circulation: 03.08.2020).

[13] Internet resource: https://www.sberbank.ru/common/img/uploaded/files/p df/analytics/potrebactivm20_262020.pdf (Date of circulation: 03.08 .2020$)$. 
[14] Internet resource:

https://www.rbc.ru/society/02/08/2020/5f26290b9a794

70e4ffebb96?from=from_main $\_1$ (Date of circulation: 03.08.2020).

[15] Internet resource:

https://www.socialbakers.com/website/storage/2020/04/ Socialbakers-COVID-19-Impact-Report.pdf (Date of circulation: 03.08.2020).

[16] Internet resource:

https://amplifieddigitalagency.com/the-benefit-ofsocial-media-marketing-during-the-coronaviruspandemic/ (Date of circulation: 03.08.2020).

[17] Internet resource:

https://www.youtube.com/watch?time continue $=2 \& v=$ qHtxQ4X2YSE\&feature=emb_logo (Date of circulation: 03.08.2020).

[18] Internet resource: https://www.instagram.com/p/B9_440DAyvZ/?utm_so urce=ig web copy link (Date of circulation:

03.08.2020).

[19] Internet resource:

https://www.facebook.com/homebargains/posts/289249 9490785986 (Date of circulation: 03.07.2020).

[20] Internet resource:

https://express.dhl.ru/mezhdunarodnaya-

dostavka/eksport-dlya-internet-magazinov/sovety-voblasti-elektronnoy-torgovli/pokupatelskoe-povedeniev-period-pandemii-covid-19-chast-2-glavnoe-v-novoyrealnosti/ (Date of circulation: 06.08.2020).

[21] Internet resource:

https://www.mckinsey.com/business-

functions/marketing-and-sales/our-insights/the-greatconsumer-shift-ten-charts-that-show-how-us-shoppingbehavior-is-changing (Date of circulation: 06.08.2020). 